\title{
Potassium Dichromate
}

National Cancer Institute

\section{Source}

National Cancer Institute. Potassium Dichromate. NCI Thesaurus. Code C45890.

An orange to red colored, crystalline, inorg anic compound that emits toxic chromium fumes upon heating. Potassium dichromate is highly corrosive and is a strong oxidizing agent. This substance is used in wood preservatives, in the manufacture of pigments and in photomechanical processes, but is mainly replaced by sodium dichromate. Potassium dichromate primarily affects the respiratory tract causing ulcerations, shortness of breath, bronchitis, pneumonia and asthma but can also affect the gastrointestinal tract, liver, kidneys and immune system. This substance is a known human carcinogen and is associated with an increased risk of developing lung cancer and cancer of the sinonasal cavity. ( $\mathrm{NCl05)}$ 